\title{
Two- and three-dimensional transvaginal ultrasound in assessment of the impact of selected obstetric risk factors on cesarean scar niche formation: the case-controlled study
}

\author{
Joanna Budny-Winska®i), Aleksandra Zimmer-Stelmach@i, Michal Pomorski@ \\ $2^{\text {nd }}$ Department and Clinic of Gynaecology, Obstetrics and Neonatology, Wroclaw Medical University, Wroclaw, Poland
}

\begin{abstract}
Objectives: Incomplete healing of the uterine scar after cesarean section may result in formation of a niche. The aim of this study is to identify the potential risk factors for the improper uterine healing after cesarean section in women with single layer, full thickness uterine closure with the use of two- and three-dimensional transvaginal ultrasonography.

Material and methods: 204 women with a history of at least one low transverse cesarean section (CS) with a single layer uterine closure participated in the study. Residual myometrial thickness (RMT), adjacent myometrial thickness (AMT), width (W), depth (D) and volume of the niche, RMT/AMT, RMT/D, RMT/W ratio and clinical characteristics were analyzed.

Results: A niche after cesarean section was found in 153 cases. However only five patients had a RMT $<2.2 \mathrm{~mm}$, and 35 had an RMT/AMT ratio $\leq 0.5$. The RMT and RMT/AMT ratio among women who had undergone more than one cesarean section was lower than among women who underwent the first cesarean section. No statistically significant relationship was found between the incidence of niche, its parameters and cervical dilation, uterine contractions, cesarean section in the second stage of labor, type of uterus incision expansion and flexion, operator's experience.

Conclusion: Healing of the uterine cesarean section scar in women with single-layer continuous suture covering the entire thickness of the myometrium, excluding the decidua is not affected by the mode of caesarean section, type of uterine incision expansion and flexion, operator's experience, stage of labor at the time of caesarean section.
\end{abstract}

Key words: cesarean section; scar niche; single layer suture; 3D ultrasonography; VOCAL; risk factors

Ginekologia Polska 2021; 92, 5: 378-382

\section{INTRODUCTION}

The consequence of each caesarean section is scar formation in the uterine muscle. In the case of incomplete healing, a niche is present within the scar. Symptoms related to the presence of uterine niches in non-pregnant women may include abnormal uterine bleeding, dysmenorrhea, chronic pelvic pain, infertility and dyspareunia [1]. According to some studies, large uterine niches eligible for surgery correction were the cause of prolonged postmenstrual spotting in $85 \%$ of patients, secondary infertility in $28 \%$ of patients and chronic pelvic pain in $14 \%$ of patients [2].

Moreover, the presence of a uterine scar niche can lead to uterine scar dehiscence/rupture in the subsequent pregnancy, as well as to caesarean scar pregnancy and to placenta accreta spectrum disorders $[3,4]$.
However, it needs to be stated that most small uterine niches are asymptomatic.

The aim of this study is to identify the potential risk factors for incomplete uterine healing after caesarean section in women with single layer, full thickness uterine closure with the use of two- and three-dimensional ultrasonography.

\section{MATERIAL AND METHODS}

In this case-controlled study, women who delivered by caesarean section (CS) at our institution from 2017 to 2019 were invited to undergo ultrasonographic assessment of the caesarean section scar 6-9 weeks after the caesarean section. The study protocol was accepted by the ethics committee and all participants signed the informed consent form before entering the study.

\footnotetext{
Corresponding author:

Joanna Budny-Winska

$2^{\text {nd }}$ Department and Clinic of Gynaecology, Obstetrics and Neonatology, Wroclaw Medical University, Poland

e-mail: Joanna.budny91@gmail.com
} 
The examinations were conducted using a Voluson V8 Expert ultrasound machine (General Electric Medical Systems) with a 4-9 MHz transvaginal 3D probe.

According to the international definition, a niche was defined as indentation of the myometrium of at least $2 \mathrm{~mm}$ [5].

The measurements were obtained in the sagittal transection of the uterus. The following parameters of niche were assessed according to the modified Delphi protocol [5] (Fig. 1):

- width of the anechoic triangle - W $(\mathrm{mm})$

- height of the anechoic triangle - D $(\mathrm{mm})$

- residual myometrial thickness - RMT (mm),

- adjacent myometrial thickness - AMT ( $\mathrm{mm})$,

- the volume of the anechoic triangle.

Additionally, the following parameters were assessed:

- the ratio of the residual myometrial thickness to adjacent myometrial thickness - RMT/AMT ratio

- the ratio of the residual myometrial thickness to the width of the anechoic triangle - the RMT/W ratio,

- the ratio of the residual myometrial thickness to the height of the anechoic triangle - RMT/D ratio.

In completely healed CS scars, when the niche was not present, only the RMT value was measured.

To create a 3D models and calculate the volume of the niche after section we used the VOCAL program (Fig. 2). The following settings were used: manual trace and rotation angle $15^{\circ}$. The boundaries of the anechoic niche were manually outlined on the touch screen of the Voluson V8 Expert ultrasound machine.

The ultrasound examinations were performed by a single operator experienced in caesarean scar assessment.

Clinical information regarding maternal medical history, pregnancy and caesarean section course were collected from medical records and analyzed after ultrasonographic assessment of the CS scar.

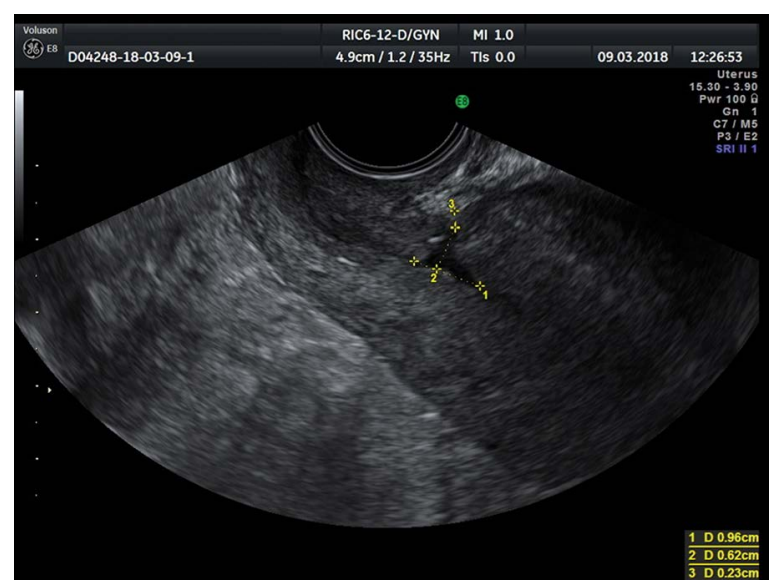

Figure 1. Measurement of the standardized cesarean section scar parameters
The inclusion criteria were as follows: low transverse uterine incision, single layer continuous full thickness uterine closure and uneventful postoperative course. There were the following exclusion criteria: vertical or inverted "T" uterine incision, double-layer uterine closure, congenital uterine malformations.

The obtained data was collected and systematized using the Excel spreadsheet tools. The statistical examination was performed using the Statistica 13.3 PL package. For quantitative variables, basic descriptive statistics were calculated (for all patients and taking into account the assumed division into groups), while for qualitative variables the frequency of occurrence of their individual variants were calculated (also taking into account the assumed division). The non-parametric test was used in the analysis (Mann-Whitney $U$ test, post and hoc comparisons for the Kruskal-Wallis ANOVA test and the non-parametric Spearman rank correlation). We used the test $\mathrm{Chi} \wedge 2$ of Pearson, $\mathrm{Chi} \wedge$ Yates or Chi $\wedge 2 \mathrm{NW}$ (depending on the group size) to search the differences in the distributions of qualitative variables. The criteria for statistical significance were set at $p<0.05$.

\section{RESULTS}

A total of 204 patients participated in this study. The study group included women with mean age of 32.25 (SD 4.156) years and gestational age 37.863 (SD 2.43) weeks. Fifty-six patients had at least one cesarean section in the past. Out of all participants, in 153 (\%) of them, a uterine niche after caesarean section was detected. The presence of the uterine niche was found in $72 \%$ of women after one caesarean section, $87 \%$ of women after two and $100 \%$ of women after three cesarean sections. Detailed characteristics of the study group are presented in Table 1.

Only five patients had a residual myometrial thickness $(\mathrm{RMT})<2.2 \mathrm{~mm}$, and 35 had an RMT / AMT ratio of 0.5 or

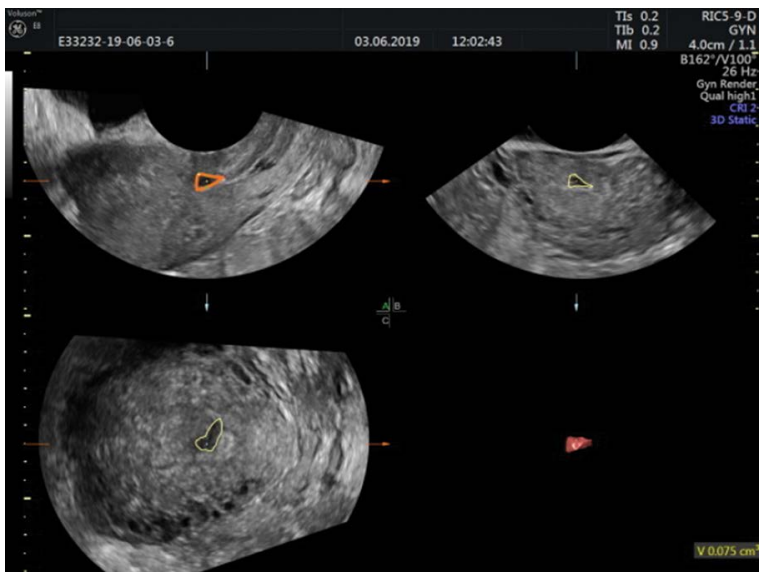

Figure 2. 3D model of cesarean scar niche 


\begin{tabular}{|c|c|c|c|c|}
\hline \multicolumn{2}{|l|}{ Variable } & Total & With niche & Without niche \\
\hline \multicolumn{2}{|l|}{ Maternal age [mean (SD)] } & $32.25(4,16)$ & $32.21(4,13)$ & $32.27(4,17)$ \\
\hline \multicolumn{2}{|l|}{ Gestational age [mean (SD)] } & $37.83(2,44)$ & $37.86(2,44)$ & $37.87(2,45)$ \\
\hline \multirow{2}{*}{ Type of CS } & Emergency [n (\%)] & $82(40 \%)$ & $63(31 \%)$ & $19(9 \%)$ \\
\hline & Planned [n (\%)] & $122(60 \%)$ & $92(45 \%)$ & $30(15 \%)$ \\
\hline \multirow{2}{*}{ Cervix dilatation } & No [n (\%)] & $163(80 \%)$ & $123(60 \%)$ & 39 (11\%) \\
\hline & $<10 \mathrm{~cm}[\mathrm{n}(\%)]$ & $41(20 \%)$ & $32(16 \%)$ & $9(4 \%)$ \\
\hline \multirow{2}{*}{ CS during II stage of labour } & No [n (\%)] & $194(95 \%)$ & $147(72 \%)$ & $47(23 \%)$ \\
\hline & Yes [n (\%)] & $10(5 \%)$ & $8(4 \%)$ & $2(1 \%)$ \\
\hline \multirow{2}{*}{ Uterus incision expansion } & Blunt [n (\%)] & $35(17 \%)$ & $27(13 \%)$ & $8(4 \%)$ \\
\hline & Sharp [n (\%)] & 169 (83\%) & $128(63 \%)$ & $41(20 \%)$ \\
\hline \multirow{2}{*}{ Number of previous CS } & No previous CS [n (\%)] & $148(73 \%)$ & $106(52 \%)$ & 42 (21\%) \\
\hline & $>1 \mathrm{CS}[\mathrm{n}(\%)]$ & $56(27 \%)$ & $49(24 \%)$ & $7(3 \%)$ \\
\hline \multirow{2}{*}{ Flexion of uterus } & Anteflexion [n (\%)] & $169(83 \%)$ & $128(63 \%)$ & $41(20 \%)$ \\
\hline & Retroflexion [n (\%)] & $35(17 \%)$ & 27 (13\%) & $8(4 \%)$ \\
\hline \multirow{2}{*}{ Operator's experience } & Resident [n (\%)] & $101(49 \%)$ & $76(37 \%)$ & $25(12 \%)$ \\
\hline & Specialist [n (\%)] & $103(51 \%)$ & $79(39 \%)$ & $25(12 \%)$ \\
\hline
\end{tabular}

SD — standard deviation; CS — caesarean section

less. Both parameters are considered risk factors for severe scar complications in subsequent pregnancies $[6,7]$.

The study did not reveal any statistically significant relationships between the parameters of the uterine caesarean scar (niche height, niche width, niche volume, residual myometrial thickness, the RMT/AMT ratio, RMT/W ratio, RMT/D ratio) and: cervical dilation, uterine contractions prior to cesarean section, caesarean section in the second stage of labor, type of uterine incision expansion (sharp vs blunt), operator's experience (resident vs specialist) or type of uterine flexion. Moreover, no statistically significant correlation was found between the occurrence of the uterine scar niche and the above-mentioned variables.

Based on the analysis, it was found that the residual myometrial thickness among women who had previously undergone at least one caesarean section was lower than among women who underwent the caesarean section for the first time $[R M T=0.69482 \mathrm{~cm}(\mathrm{SD}=0.37705)$ vs $\mathrm{RMT}=0.88088 \mathrm{~cm}$ $(S D=0.30718) ; p=0.000068]$. Similar relationship was demonstrated for the RMT/AMT ratio. The individual results are presented in Tables 2, 3.

\section{DISCUSSION}

Due to the increasing number of caesarean sections and, consequently, the increasing number of side effects related to incomplete healing process of the uterine scar, there are worldwide efforts trying to define factors that affect uterine healing.
In this study, the evaluation of the uterine scar niche was performed using 2D and 3D unenhanced transvaginal ultrasound 6-9 weeks after caesarean section. Calculation of the niche volume and preparation of the 3D model of the niche, enabled precise evaluation of the niche. In most of previous studies the caesarean section scar was assessed only with the use of two dimensional ultrasonography [1-4, 7-12].

The aim of our study was to assess the dependence of niche parameters after caesarean section in relation to individual variables, to determine which factors can lead to the niche formation. Thus, each diagnosed niche was included in the statistical analysis, and not only those niches which can be classified as large [5] ${ }^{\vee}$ or those which cause clinical symptoms [4].

In our study, as in other studies, the relationship between the number of previous caesarean sections and the risk of uterine niche formation was confirmed [1, 8-10]. The study found no correlation between the incidence of uterine scar niches and the mode of caesarean section (emergency/elective), which is supported by other studies [10,13]. However, our study revealed that RMT, RMT/AMT ratio and RMT/W ratio are lower in women who underwent elective caesarean section versus those who underwent emergency caesarean section. Such relationship can be explained by the disproportion in size and heterogeneity of both groups.

In the search for potential factors that may affect the healing of the uterine scar after caesarean section, the influence of uterine contractions prior to caesarean section, dilation of the cervix, and thus the progress of labor, cannot 


\begin{tabular}{|c|c|c|c|c|c|c|c|c|c|}
\hline \multicolumn{2}{|l|}{ Variable } & $\begin{array}{l}\text { Width (W) } \\
\quad[\mathrm{cm}]\end{array}$ & $\begin{array}{l}\text { Height (H) } \\
\quad[\mathrm{cm}]\end{array}$ & $\mathrm{RMT}[\mathrm{cm}]$ & $\mathrm{AMT}[\mathrm{cm}]$ & RMT/AMT & RMT/W & RMT/H & $\begin{array}{c}\text { Volume } \\
{\left[\mathrm{cm}^{3}\right]}\end{array}$ \\
\hline \multirow{2}{*}{ Type of CS } & Emergency & 0.77 & 0.48 & 0.89 & 1.3 & 0.62 & 1.24 & 2.08 & 0.14 \\
\hline & Planned & 0.85 & 0.51 & 0.79 & 1.26 & 0.58 & 1.08 & 1.75 & 0.16 \\
\hline \multirow{2}{*}{ Cervix dilatation } & No & 0.88 & 0.54 & 0.84 & 1.27 & 0.6 & 1.01 & 1.69 & 0.16 \\
\hline & $<10 \mathrm{~cm}$ & 0.8 & 0.49 & 0.83 & 1.28 & 0.58 & 1.18 & 1.93 & 0.15 \\
\hline \multirow{2}{*}{$\begin{array}{l}\text { CS during II } \\
\text { stage of labour }\end{array}$} & No & 0.82 & 0.5 & 0.83 & 1.28 & 0.6 & 1.14 & 1.89 & 0.15 \\
\hline & Yes & 0.73 & 0.44 & 0.83 & 1.19 & 0.62 & 1.17 & 1.74 & 0.09 \\
\hline \multirow{2}{*}{$\begin{array}{l}\text { Uterus incision } \\
\text { expansion }\end{array}$} & Blunt & 0.83 & 0.5 & 0.84 & 1.29 & 0.6 & 1.13 & 1.94 & 0.15 \\
\hline & Sharp & 0.77 & 0.52 & 0.79 & 1.22 & 0.56 & 1.2 & 1.62 & 0.14 \\
\hline \multirow{2}{*}{$\begin{array}{l}\text { Number of pre- } \\
\text { vious CS }\end{array}$} & No previous CS & 0.81 & 0.49 & 0.88 & 1.32 & 0.62 & 1.2 & 2.01 & 0.13 \\
\hline & $>1 \mathrm{CS}$ & 0.84 & 0.51 & 0.69 & 1.17 & 0.55 & 1.02 & 1.61 & 0.19 \\
\hline \multirow{2}{*}{$\begin{array}{l}\text { Flexion of } \\
\text { uterus }\end{array}$} & Anteflexion & 0.81 & 0.49 & 0.84 & 1.27 & 0.6 & 1.14 & 1.92 & 0.15 \\
\hline & Retroflexion & 0.84 & 0.55 & 0.8 & 1.29 & 0.58 & 1.17 & 1.71 & 0.15 \\
\hline \multirow{2}{*}{$\begin{array}{l}\text { Operator's ex- } \\
\text { perience }\end{array}$} & Resident & 0.82 & 0.51 & 0.85 & 1.29 & 0.59 & 1.14 & 1.88 & 0.13 \\
\hline & Specialist & 0.82 & 0.49 & 0.81 & 1.26 & 0.6 & 1.15 & 1.88 & 0.16 \\
\hline
\end{tabular}

Significant correlations at level of $\mathrm{p}<0.05$ are marked in bold; RMT — residual myometrial thickness; AMT — adjacent myometrial thickness; CS — cesarean section

Table 3. Correlations between incidence of uterine niche and analyzed variables

\begin{tabular}{|c|c|c|c|c|c|c|c|c|c|c|}
\hline \multirow{2}{*}{ Variable } & \multicolumn{2}{|c|}{ Type of CS } & \multicolumn{2}{|c|}{$\begin{array}{c}\text { Contractions prior } \\
\text { to CS }\end{array}$} & \multicolumn{2}{|c|}{$\begin{array}{c}\text { Uterus incision } \\
\text { expansion }\end{array}$} & \multicolumn{2}{|c|}{ Operator's experience } & \multicolumn{2}{|c|}{ Flexion of uterus } \\
\hline & $\begin{array}{c}\text { Emergency } \\
\text { [n (\%)] }\end{array}$ & $\begin{array}{l}\text { Planned } \\
\text { [n (\%)] }\end{array}$ & $\begin{array}{c}\text { Yes } \\
{[n(\%)]}\end{array}$ & $\begin{array}{c}\text { No } \\
{[n(\%)]}\end{array}$ & $\begin{array}{l}\text { Blunt } \\
\text { [n (\%)] }\end{array}$ & $\begin{array}{l}\text { Sharp } \\
{[n(\%)]}\end{array}$ & $\begin{array}{l}\text { Resident } \\
\text { [n (\%)] }\end{array}$ & $\begin{array}{l}\text { Specialist } \\
{[n(\%)]}\end{array}$ & $\begin{array}{l}\text { Anteflexion } \\
\text { [n (\%)] }\end{array}$ & $\begin{array}{l}\text { Retroflexion } \\
\text { [n (\%)] }\end{array}$ \\
\hline Niche & $\begin{array}{c}62 \\
(40.52 \%)\end{array}$ & $\begin{array}{c}91 \\
(59.48 \%)\end{array}$ & $\begin{array}{c}9 \\
(17.65 \%)\end{array}$ & $\begin{array}{c}121 \\
(79.08 \%)\end{array}$ & $\begin{array}{c}27 \\
(17.65 \%)\end{array}$ & $\begin{array}{c}126 \\
(82.35 \%)\end{array}$ & $\begin{array}{c}76 \\
(49.67 \%)\end{array}$ & $\begin{array}{c}77 \\
(50.33 \%)\end{array}$ & $\begin{array}{c}125 \\
(82.24 \%)\end{array}$ & $\begin{array}{c}27 \\
(17.65 \%)\end{array}$ \\
\hline Non-NICHE & $\begin{array}{c}20 \\
(39.22 \%)\end{array}$ & $\begin{array}{c}31 \\
(60.78 \%)\end{array}$ & $\begin{array}{c}32 \\
(20.92 \%)\end{array}$ & $\begin{array}{c}42 \\
(82.35 \%)\end{array}$ & $\begin{array}{c}8 \\
(15.69 \%)\end{array}$ & $\begin{array}{c}43 \\
(84.31 \%)\end{array}$ & $\begin{array}{c}25 \\
(49.02 \%)\end{array}$ & $\begin{array}{c}26 \\
(50.98 \%)\end{array}$ & $\begin{array}{c}43 \\
(84.31 \%)\end{array}$ & $\begin{array}{c}8 \\
(15.69 \%)\end{array}$ \\
\hline $\mathrm{p}$ value & \multicolumn{2}{|c|}{$p=0.86903$} & \multicolumn{2}{|c|}{$p=0.76218$} & \multicolumn{2}{|c|}{$p=0.91461$} & \multicolumn{2}{|c|}{$p=0.93556$} & \multicolumn{2}{|c|}{$p=0.90008$} \\
\hline
\end{tabular}

CS - cesarean section

be ignored. There are conflicting conclusions in the literature regarding the impact of these variables on the healing process of the uterus. In the study of Yazicioglu et. al. [11], it has been shown that smaller cervical dilatation at the time of caesarean section is a risk factor for incomplete uterine healing ${ }^{\mathrm{xi}}$. However other studies have shown lower RMT values in women who underwent caesarean section in the second stage of labor [12]. In our study, no correlation was found between the incidence of niches after caesarean section and dilatation of cervix, contractions prior to caesarean section, performance of caesarean section during the second stage of labor. Also, no influence of the above-mentioned factors on niche parameters was found.

To the best of our knowledge this is the first study that assessed the type of uterine incision expansion (sharp vs blunt) and surgeons experience (specialist vs resident) on the healing of the caesarean section scar. In the previous studies, only the parameters related to the postoperative course were assessed. Thus, in the meta-analysis by Saad et al. [13] it was found that blunt opening of the uterus was associated with a lower decrease in hematocrit and postoperative hemoglobin level, a lower percentage of unintended openings and a shorter operation time. The analysis carried out in our study did not show a statistically significant difference between the frequency of the niche occurrence and the parameters of the niche depending on the type of uterine incision expansion and surgeons experience. This can be explained by the use of unified uterine closure technique - single layer, continuous full thickness suture, excluding the decidua.

Another issue assessed in the study was the type of flexion of the uterus. Our study found no correlation between the uterine retroflexion and the presence of the uterine scar niche, and no negative correlation between retroflexion and 
residual myometrial thickness (RMT), despite the fact that such an association is reported in the literature $[3,7,14]$. Most likely, it is associated with a small group of women with uterine retroflexion in our study.

\section{CONCLUSIONS}

Healing of the uterine caesarean section scar assessed with the use of 2D/3D ultrasonography in women with single-layer continuous suture covering the entire thickness of the myometrium, excluding the decidua is not affected by the mode of caesarean section, type of uterine incision expansion, operator's experience, uterine flexion and stage of labor at the time of caesarean section.

\section{Conflict of interest}

None declared.

\section{REFERENCES}

1. Wang CB, Chiu WW, Lee CY, et al. Cesarean scar defect: correlation between Cesarean section number, defect size, clinical symptoms and uterine position. Ultrasound Obstet Gynecol. 2009; 34(1): 85-89, doi: 10.1002/uog.6405, indexed in Pubmed: 19565535.

2. Pomorski M, Fuchs T, Rosner-Tenerowicz A, et al. Sonographic evaluation of surgical repair of uterine cesarean scar defects. J Clin Ultrasound. 2017; 45(8): 455-460, doi: 10.1002/jcu.22449, indexed in Pubmed: 28186617.

3. Osser OV, Jokubkiene L, Valentin L. High prevalence of defects in Cesarean section scars at transvaginal ultrasound examination. Ultrasound Obstet Gynecol. 2009; 34(1): 90-97, doi: 10.1002/uog.6395, indexed in Pubmed: 19499514.

4. Donnez O, Donnez J, Orellana R, et al. Gynecological and obstetrical outcomes after laparoscopic repair of a cesarean scar defect in a series of 38 women. Fertil Steril. 2017; 107(1): 289-296.e2, doi: 10.1016/j. fertnstert.2016.09.033, indexed in Pubmed: 27816234.
5. Jordans IPM, de Leeuw RA, Stegwee SI, et al. Sonographic examination of uterine niche in non-pregnant women: a modified Delphi procedure. UItrasound Obstet Gynecol. 2019; 53(1): 107-115, doi: 10.1002/uog.19049, indexed in Pubmed: 29536581.

6. Pomorski M, Fuchs T, Zimmer M. Prediction of uterine dehiscence using ultrasonographic parameters of cesarean section scar in the nonpregnant uterus: a prospective observational study. BMC Pregnancy Childbirth. 2014; 14: 365, doi: 10.1186/s12884-014-0365-3, indexed in Pubmed: 25733122

7. Vikhareva Osser O, Valentin L. Clinical importance of appearance of cesarean hysterotomy scar at transvaginal ultrasonography in nonpregnant women. Obstet Gynecol. 2011; 117(3): 525-532, doi: 10.1097/AOG.0b013e318209abfo, indexed in Pubmed: 21343754

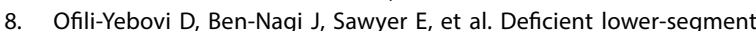
Cesarean section scars: prevalence and risk factors. Ultrasound Obstet Gynecol. 2008; 31(1): 72-77, doi: 10.1002/uog.5200, indexed in Pubmed: 18061960.

9. Chen Y, Han P, Wang YJ, et al. Risk factors for incomplete healing of the uterine incision after cesarean section. Arch Gynecol Obstet. 2017; 296(2): 355-361, doi: 10.1007/s00404-017-4417-6, indexed in Pubmed: 28589479.

10. Armstrong V, Hansen WF, Van Voorhis BJ, et al. Detection of cesarean scars by transvaginal ultrasound. Obstet Gynecol. 2003; 101(1): 61-65, doi: 10.1016/s0029-7844(02)02450-x, indexed in Pubmed: 12517646.

11. Yazicioglu F, Gökdogan A, Kelekci S, et al. Incomplete healing of the uterine incision after caesarean section: Is it preventable? Eur J Obstet Gynecol Reprod Biol. 2006; 124(1):32-36, doi: 10.1016/j.ejogrb.2005.03.023, indexed in Pubmed: 16023780.

12. Antila-Långsjö RM, Mäenpää JU, Huhtala HS, et al. Cesarean scar defect: a prospective study on risk factors. Am J Obstet Gynecol. 2018; 219(5): 458.e1-458.e8, doi: 10.1016/j.ajog.2018.09.004, indexed in Pubmed: 30240650 .

13. Saad AF, Rahman M, Costantine MM, et al. Blunt versus sharp uterine incision expansion during low transverse cesarean delivery: a metaanalysis. Am J Obstet Gynecol. 2014; 211(6): 684.e1-684.11, doi: 10.1016/j. ajog.2014.06.050, indexed in Pubmed: 24983682

14. Pomorski M, Fuchs T, Rosner-Tenerowicz A, et al. Standardized ultrasonographic approach for the assessment of risk factors of incomplete healing of the cesarean section scar in the uterus. Eur J Obstet Gynecol Reprod Biol. 2016; 205: 141-145, doi: 10.1016/j.ejogrb.2016.08.032, indexed in Pubmed: 27591715. 